\title{
Decision Framework for Engaging Cloud- Based Big Data Analytics Vendors
}

\author{
Emmanuel Wusuhon Yanibo Ayaburi, University of Texas Rio Grande Valley, USA \\ Michele Maasberg, Louisiana Tech University, USA \\ (iD https://orcid.org/0000-0003-4306-0559
}

Jaeung Lee, Louisiana Tech University, USA

\begin{abstract}
Organizations face both opportunities and risks with big data analytics vendors, and the risks are now profound, as data has been likened to the oil of the digital era. The growing body of research at the nexus of big data analytics and cloud computing is examined from the economic perspective, based on agency theory (AT). A conceptual framework is developed for analyzing these opportunities and challenges regarding the use of big data analytics and cloud computing in e-business environments. This framework allows organizations to engage in contracts that target competitive parity with their service-oriented decision support system (SODSS) to achieve a competitive advantage related to their core business model. A unique contribution of this paper is its perspective on how to engage a vendor contractually to achieve this competitive advantage. The framework provides insights for a manager in selecting a vendor for cloud-based big data services.
\end{abstract}

\section{KEYWORDS}

Agency Theory, Big Data Analytics, Cloud Computing, Competitive Advantage, Competitive Parity, E-Business

\section{INTRODUCTION}

The proliferation of mobile devices and the ability of almost any electronic device to connect to the Internet have significantly increased the amount of data generated by businesses daily. This increase in the magnitude of data is called big data (Hashem et al., 2015); it is difficult to store, process, and analyze using traditional tools, such as relational databases. Big data is distinguished from traditional data by volume, velocity, variety, veracity, and value (Marr, 2015). These characteristics help business managers to make important decisions in real time (Höchtl, Parycek, \& Schöllhammer, 2016). The nature and origin of these characteristics can be explained by the data life cycle where a business collects, stores, processes, and makes meaning out of the data at their disposal from generation to insight. Figure 1 illustrates a typical data life cycle where a business uses the insights obtained from the processed data to gather more data. The data life cycle process leads to challenges that typical 


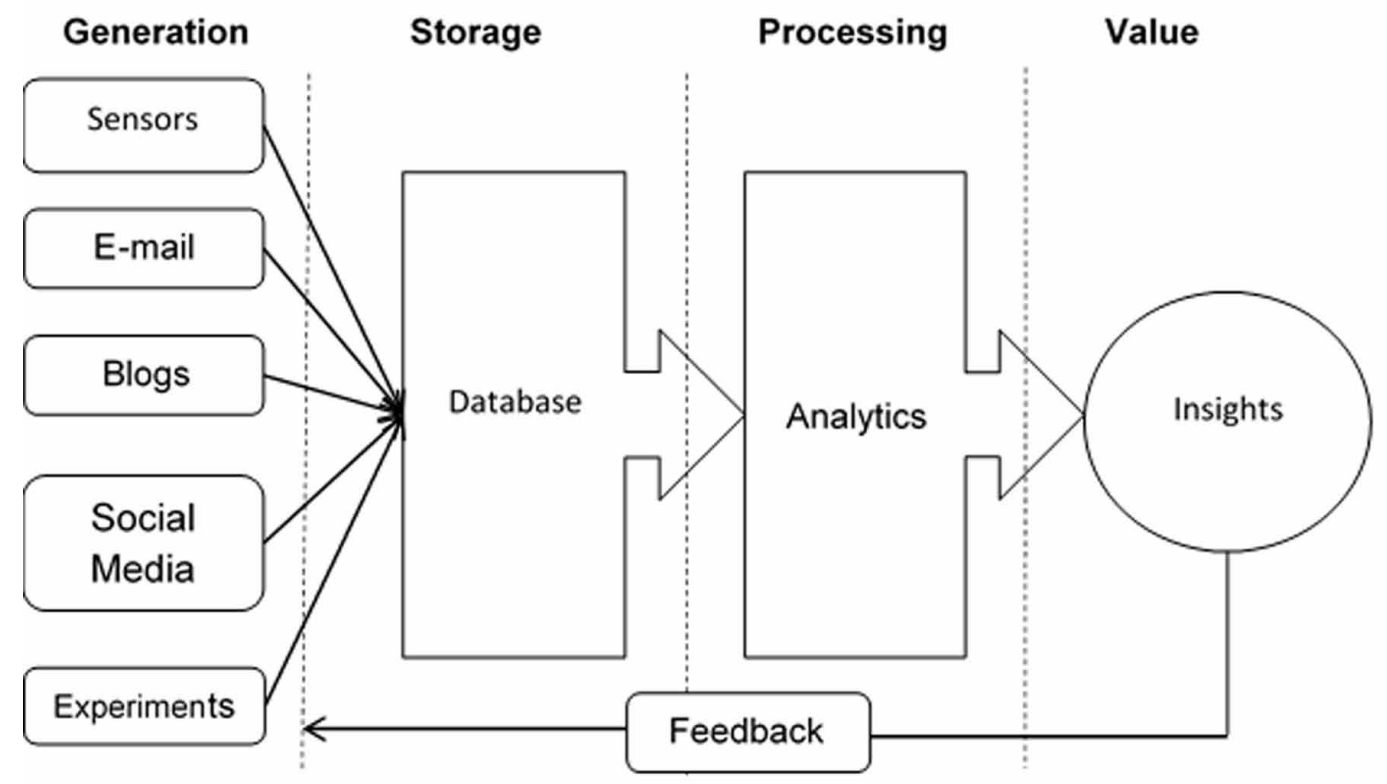

businesses do not face in their daily operations in dealing with big data, often prohibiting insights if the business is unprepared to handle them.

Many organizations are unable to manage their existing smaller data, and big data adds a layer of complexity, as capabilities are necessary with analytics and storage (Troester, 2012). Thus, despite the pervasiveness of big data technologies, many e-business firms are unable to achieve the elusive status of success (Gupta \& George, 2016).

This study posits that one explanation for organizations missing out on the success of big data relates to the nature and effect of the contract between vendors providing cloud-based data analytic services and clients receiving those services. Among the opportunities for big data and analytics in the cloud is an ecosystem conceptually referred to as a Service-Oriented Decision Support System (SODSS). Demirkan and Delen (2013) suggest that value can be created through the implementation of accrued knowledge from the interactions of service systems that involve people, technology, organizations, and shared information. There are challenges as vendors, usually third parties, are required to manage these processes unless the core competency of the organization is technology, particularly related to big data, analytics, and the cloud. This study complements prior studies such as Pakath (2015) and Yu (2016) that provide insights for businesses to create value from big data analytics. This study seeks to enhance understanding of economic benefits of analytics literature by investigating the following research questions:

Question 1: What challenges do e-business organizations face in using cloud-based big data analytics?

Question 2: What decision factors should e-business organizations consider in their contracts with agents regarding cloud-based big data analytics to achieve competitive parity?

Question 3: How should e-business organizations manage their contracts with cloud-based big data analytics vendors?

In response to these questions, this study develops a theoretical framework to understand the opportunities and challenges of big data analytics in cloud computing for e-businesses (Amit \& Zott, 
2001) from an economic perspective to maximize competitive parity (Mata, Fuerst, \& Barney, 1995). The findings provide insights to e-business firms into how they can make the most from the potential data available to them and understand the challenges in the process, particularly their decision-making regarding the type of vendor for big data. The rate of adoption of data analytics tools suggests that most firms would continue to use the services of third-party vendors. An examination of client decisions and issues in contracting vendors reduces uncertainties in adopting analytics.

\section{BACKGROUND: CLOUD-BASED DATA ANALYTICS CHALLENGES}

\section{Data Scalability and Availability}

The rise of big data, from the proliferation of sensors and the ability to measure things at minute levels, has led to the production of petabytes of data in almost all kinds of electronic business. Much of this data is of little interest and should be filtered. Cloud providers still lack round-the-clock service as they experience outages, notable among these is the famous Amazon Web Services (AWS) 2012 outage (Williams, 2012). This places extra responsibility on e-business firms to monitor their services. Some businesses use internal or third-party tools to supervise usage, Service Level Agreements (SLAs), performance, robustness, and business dependency.

\section{Data Integrity}

The data gathered in electronic transactions do not always come in a form that can be effectively analyzed. However, collecting data at the original sources and aggregating them can be a technical challenge for most e-business firms. Therefore, generated big data might not always be giving accurate information. For example, reviewers sometimes misinform other reviewers, and customer service personnel may not process customer complaints they deem detrimental to their jobs. This presents challenges regarding the validity of gathered data.

\section{Data Quality}

Big data can be highly noisy, dynamic, untrustworthy, inter-related, and heterogeneous (Xindong Wu, Xingquan Zhu, Gong-Qing Wu, \& Wei Ding, 2014). Nonetheless, big data is still valuable because information obtained from the analysis of data or web mining usually empowers individuals, leading to the discovery of hidden patterns and knowledge. Information redundancy can help compensate for missing data and enhance the efficiency of these analyses. The value of big data analysis in e-business is enhanced if analysis can be done robustly under difficult conditions such as limited data. The quality of the needed information depends on the ability to coordinate disparate database systems. Despite advances in cloud-based analytics, gathering high-quality data from e-business sites is still a challenge (Xindong Wu et al., 2014).

\section{Loss of Control}

Some concerns of e-business firms' transitioning to cloud-based big data analytics include security and privacy of customer data (Chen, Chiang, \& Storey, 2012). This is because data that resides outside the corporate firewall presents data owners' challenges in the exercise of control and oversight in data protection. Cloud infrastructure hacking can affect multiple clients. E-business firms would have to incur extra cost to purchase additional security applications and encrypt files across several servers (Chen et al., 2012).

\section{Lock-In}

SLA of some cloud-based big data analytics providers may be inadequate to guarantee availability, scalability, and ease of data mobility (Subashini \& Kavitha, 2011). Thus, some e-business firms may have justified concerns when things that are not under their control go wrong. The loss of control 
over data to the cloud provider is a valid concern when the accountability for the safety, security, and proper use of its business data are poorly negotiated in cloud-based big data analytics contracts (Subashini \& Kavitha, 2011). One key recommendation for selecting the service provider is for an e-business firm to have an alternative for cloud disaster recovery, in case the disaster is a bankrupt service provider (Behrend et al., 2011). This reduces their exposure to being locked into one provider.

\section{THEORY AND DECISION FRAMEWORK FOR ECONOMIC ANALYSIS}

\section{Agency Theory in Cloud-Based Big Data Analytics for E-Business}

Agency Theory $(A T)$ deals with issues that arise when two or more parties are engaged in a transaction in which a decision made by one party affects the other parties in the transactions. Actions and decisions by vendors of big data analytics affect the relationship with e-business firms. AT highlights issues of goal incongruence between an agent (cloud big data analytics vendors and brokers) and a principal (e-business user firms). Some have applied it in other areas, such as understanding outsourcing relationships (Tiwana \& Bush, 2007). AT suggests that information asymmetry is the underlying key to understanding principal-agent problems, as the agent is assumed to possess private information about the type and nature of cloud-based big data analytics services that the principal is not privy to, or can only be able to acquire with added cost and effort. Instituting behavioral and outcome controls in contracts as suggested by AT to protect e-business clients will only be successful if the principal (client firm) can confidently specify current and future requirements for the privacy and security of its data generation and analytic activities. Extra demands from principals will not always be in the agent's (service providers) interests as it requires charging the client extra for anything that is not in the contract. That will ultimately affect the provider's profitability (Gottschalk \& Solli-Sæther, 2005). With the inability to negotiate a contract that covers every possible situation (Bakos \& Brynjolfsson, 1993), some cloud-based analytics providers could hide behind their inefficiencies to fully deliver their substandard services, such as insecure virtualization. Providers may blame any non-favorable outcomes to outside forces.

\section{Agents}

\section{Cloud Vendors}

Client firms using cloud-based services such as Infrastructure as a Service (IaaS) can pay for exactly the amount of service used, similar to electricity, water, and storage services. This ability to pay as needed enables firms to store more data generated during their operation without having to worry about limitations to their physical devices. As a result, data can be generated in large volumes and at a faster rate than before. Thus, the big data phenomenon is largely driven by the ability of firms to generate and store data with little or no constraints. Some examples of IaaS providers include AWS, which offers computation and storage services, Windows Azure, which is believed to be a natural fit for clients working on Microsoft platforms, Google Cloud Storage, Google BigQeury, and Google Cloud SQL. Additionally, Google Compute Engine is also touted to be best suited for big data, data warehousing, high-performance computing, and other analytics-focused applications such as Rackspace Open Cloud, IBM SmartCloud Enterprise, and HP Enterprise Converged Infrastructure.

\section{Cloud Brokers/Integrators}

Cloud Service Brokerage (CSB) functions as intermediaries between client firms and cloud service providers. The intermediary services provided by these brokerages include aggregating multiple cloud services and integrating cloud services with in-house apps. In some instances, these brokerages provide customizable cloud services to meet the needs of clients. The three roles for CSBs are aggregation, integration, and customization. A CSB-as-aggregator pulls together multiple cloud services and provides them to the end customer, essentially acting as a reseller. The integration role, meanwhile, 
calls for the broker to link cloud services and on-premises systems while customization involves the tweaking of cloud services to meet the customer's needs or the creation of applications to run in the cloud setting. Some examples of brokers include AWS Marketplace, Dell Boomi, Rackspace Cloud Tools Marketplace, SoftChoice Cloud, and SaaSMax. Annual IT spending on these CSB services is forecasted to reach approximately $\$ 160$ billion by 2018 (Gartner, 2015).

\section{Cloud-Based Big Data Analytics Contract Challenges}

\section{Agent Underperformance}

E-business firms expect the continuous provision of cloud services year-round to deliver flawless services to their clients. These goals will be hampered severely if their IT infrastructure is unavailable since their entire operation is online. Contracts in the form of SLAs of most cloud providers such as AWS promise $99 \%$ availability and with a promise to pay for any downtime (Amazon Web Services, 2013). However, these come with caveats such as establishing the cause of downtime to be reasonably within the service provider's control, prompting some industry experts such as Gartner researchers to describe such cloud SLAs as having little usefulness. It is, therefore, very possible for service providers to blame underperformance, from service outages to the caveats in their SLAs, to minimize their losses. A case in point is the famous outage of AWS for 23 hours affecting service to Netflix and other online businesses around Christmas Eve in 2012 when media service providers such as Netflix are in peak demand. AWS attributed this challenge to failures in its load balancers and offered its standard apologies to make up for it (Mann, 2013). Therefore, it is challenging for e-business firms to graciously hand over their mission-critical services to third-party cloud-based big data analytics vendors for fear it might go down for almost a whole day with immeasurable negative consequences and no compensation. Firms' inability to assess vendors' capabilities and SLA caveats properly creates asymmetries in information, which leads to heightened chances of moral hazards (Pallas, 2014). E-business firms bear more risk than service providers in these transactions. Prior studies, such as Mao, Lee, \& Deng, (2008) suggest that client firms' trust in or control over the vendor could improve the performance of the vendor.

\section{Agent Shirking}

Cloud-based big data analytics operate under the premise that integrated resources are better used than disparate ones because users have varying demands for computing resources at different times. Aggregating these computing and analytic demands, service providers can meet the needs of many e-business firms with limited resources compared to each firm having their own computing resources. This is no minor task for service providers, as they need to accurately predict user requirements and invest in analytic, server, spare, and backup capacities in an optimal manner. Excess investments in these areas means increased costs for vendors, which ultimately get transferred to the e-business firms requiring their services. Thus, cloud vendors are in a constant dilemma about their investments in capacity, since their goal is to maximize the benefits for their shareholders and not their clients. This creates information asymmetries about how to guarantee services from adequate server capacity/backups and maximizing vendor profits. Clients unaware of these capacities could encourage vendors to shirking their responsibility to provide backups for clients, as stated in most SLAs. Vendors expect clients to attribute poor services to a spike in demand for services from multiple clients. For instance, Nirvanix, a cloud storage service headquartered in San Diego, in pursuit of their singular goal of maximizing value for its creditors, shirked their responsibility to provide continuous storage services to their clients as stated in their SLA and decided to close their services by filing chapter 11 bankruptcy protections (Lowe, 2013). Although alternative plans were made to transfer its customers to IBM, most of their clients were unaware of prior actions of their providers until they received their two weeks' notice. Little thought was given to how the change of service providers would impact their clients' business. 


\section{Data Poaching and IP Theft}

As these e-business firms share the same resources, vendors must provide another layer of security such that rival firms do not have access to data of a competitor. Increased data federation and protection of firm data increase the operational cost of vendors as there is the need to monitor data centers constantly for breaches. However, user firms, such as e-business firms located in Europe, are required by the European Union (EU) regulations to store their data within the EU. For instance, as of October 2015, it is illegal for storage providers to transfer data outcomes from the EU to the US, even if that is an economically viable option leading giant cloud vendors such as AWS and Facebook to start building full-scale data centers in Europe (Drozdiak \& Schechner, 2015). For example, Box. com, an online file sharing and personal cloud content management service for businesses handed a user's entire account over to a stranger, who removed the client's account (Tynan, 2013). Although Box.com was able to find the cause and implement new procedures to prevent future occurrence, this human error heightens the concern of moral hazards for e-business firms wanting to adopt cloudbased big data analytic tools. For example, rival firms in Europe could end up having their data stored next to each other in the same data center, and if the data center suffers from "Box.com syndrome," the consequence could be far more disastrous. Thus, the fear of IP theft is real for e-business firms. Vendors' motivation to provide this additional layer of protection in addition to building data centers contained within a geographical location remains an open question. Considering the challenges discussed here, this study proposes that:

Proposition 1: E-business firms will be more likely to use cloud-based big data analytics services when brokers and vendors show competence in handling contractual challenges.

\section{Transaction Challenges}

\section{Transaction Costs}

Transaction costs arise because it is impossible to write a comprehensive contract to cover all possible situations, giving rise to subsequent renegotiations when the balance of power between the transacting parties shifts (Williamson, 1979). If transaction costs offset production cost advantages of the external supplier, the firm subsumes the activity. Using Transaction Cost Economics (TCE) as their theoretical basis for argument, Ang \& Straub (1998) concluded that the sourcing decision is often seen as a rational decision made by firms that have considered transaction-related factors such as asset specificity, environmental uncertainty, and other types of transaction costs. Whenever an activity is conducted under conditions of high uncertainty, or whenever an activity requires specific assets, transaction costs, the costs of writing, monitoring, and enforcing contracts are likely to be high. When transaction costs are high, outsourcing is deemed to be relatively inefficient compared with internal, hierarchical administration (Gottschalk \& Solli-Sæther, 2005). Increased legislation about the storage location of cloud data has been a global issue. Therefore, the direct and indirect expenses (TCE) of negotiating, monitoring, and enforcing explicit and implicit contracts between a client firm and cloud big data analytic vendors will guide the initial decision to use cloud-based data analytic services (Tiwana \& Bush, 2007).

\section{Network Externalities}

An externality, or spillover effect, is a cost or benefit that is incurred by someone who is not involved in the trade. Positive network externalities are a form of benefit arising from a network when the value of adding an extra node or edge is felt by every other part of the network (Liu, Gal-Or, Kemerer, \& Smith, 2011). Technological changes that allow us to connect and share data more easily are disrupting established business models. Network externalities occur in the case of data because data is only informative when it is interpreted. The value of each datum increases with the volume of other data 
that it may be connected with as the context and range of analysis that is possible increases (Gower, 2012). This has prompted some to advocate for open data. This is because data is typically nonexcludable, implying that prohibiting the sharing of data in many cases is practically unenforceable.

\section{Switching Costs}

Gottschalk \& Solli-Sæther, (2005) concluded in their study of critical success factors of IT outsourcing that organizations can minimize transaction costs by relying less on specific IT assets, increasing transaction frequency, and reducing complexity and uncertainty in IT tasks. However, software stacks in cloud computing have improved interoperability among platforms, but with little standardization, most of the storage APIs for cloud computing are still proprietary or at least have not been the subject of active standardization (Armbrust et al., 2010). Thus, client firms who use cloud-based big data analytics cannot easily extract their data and programs from one site to run on another or easily switch between service providers. Concern about data-lock-in is preventing some organizations from adopting cloud computing. Although lock-in is desirable to service providers, client firms are susceptible to price increases and reliability problems because of increased switching costs. For instance, on August 8, 2008, online storage service provider, The Linkup, formerly known as MediaMax, could not account for $45 \%$ of customer data after it shut down due to failure in their attempt to move files of over 20,000 customers to a different platform (Brodkin, 2008).

\section{Adverse Selection and Incomplete Contracts}

Adverse selection, a related agency problem, could occur when the analytics service provider has relevant private information unknown to its clients. The asymmetry of information may lead an e-business firm to make bad decisions, such as doing more business with less profitable or riskier cloud providers. Usually, the shorter the time frame of the service arrangement, the less time each party will invest in writing a contract. For the uncertainty of the future, if a third party service arrangement is for a long time, parties will invest more time designing contracts that will protect their future bargaining powers (Holdup) subsequently resulting in the writing of an extensive contract (Susarla, Subramanyam, \& Karhade, 2010). Thus, the SLA between client firms and service providers might not cover aspects of the usage of cloud-based big data analytics leading to an incomplete contract (Bakos \& Brynjolfsson, 1993). The potential adverse selection on the part of e-business firms or issues arising from the incomplete nature of the contract (SLA) could lead to higher switching costs or transaction costs for client firms (Tuttle, Harrell, \& Harrison, 1997). This suggests that:

Proposition 2: The higher the level of network effects generated using cloud-based analytics, the less likely the e-business organization will be concerned about transaction uncertainty such as possible switching cost or adverse vendor selection.

\section{Countermeasures}

\section{Monitoring}

AT generally focuses on problems of providing incentives in a variety of settings (McAfee \& McMillan, 1986, 1987). To mitigate the moral hazard problems caused by agents, principals implement incentivebased contracts that compensate agents based on observable outcomes. Incentive mechanisms and monitoring of any contract result in the reduction of uncertainty, especially when information is constantly updated over the course of the contract. Benchmark, as a form of monitoring agent actions, can help reduce uncertainty about the capabilities of vendors and the consequences of their actions. Although cloud vendors have information about the quality of their cloud-based data analytic tools in data generation, integration, security controls, and status of the standards of their technologies, user client firms might lack the appropriate capability to assess these capabilities. Industry experts such as Gartner, IDC, Forrester, and TalkinCloud are better positioned to evaluate the capabilities 
and behaviors of vendors than user firms. These industry experts annually evaluate vendors and rank vendors in reports such as the Gartner magic quadrant and the Talkin' Cloud 100 Report (e.g., Gartner magic quadrant 2014 and 2015 and Talkin' Cloud 100 Report 2014 and 2015). As the audiences of these reports include big client firms, vendors will implement systems that produce quality information to user firms, rather than peruse opportunistic behavior to the detriment of their user client firms. Vendors will try to maintain good ratings in these reports to attract business, gain the trust of potential clients, and avoid the negative effect low ranking will have on their stocks. Also, the vendor firm leadership gets extra compensation for achieving or maintaining good rankings.

\section{Screening and Signaling}

Third party cloud-based data analytics is a form of outsourcing. Like firms engaged in outsourcing contracts, e-business firms using cloud-based analytics are also confronted with the issue of incomplete contracts in guiding the behavior of parties involved in the transaction. Vendors aiming at maximizing their revenue might oversell their capabilities, or clients might not be able to fully document their analytics needs as these may change over time. Information asymmetry or incomplete contracts could give rise to agency problems. AT suggests that a principal could reduce its chances of suffering opportunistic behavior problems by having an appropriate contract that reduces the information asymmetry between them and their vendors (Eisenhardt, 1989). It is in the crafting of these contracts and the actual implementation of these contracts that the expertise of Brokers and Integrators of cloud-based big data analytics are necessary.

Based on the information and services provided by brokers and integrators, user firms can pick up signals about the potential of vendors and screen out vendors that will likely deliver unsatisfactory results. Effective signals allow brokers and vendors who deliver quality service to differentiate from those who deliver substandard service (Pavlou, Liang, \& Xue, 2007). Therefore:

Proposition 3: The more efficient the countermeasures (i.e., monitoring, signaling, and screening) are in the industry, the less likely e-business firm will be concerned about contracts with vendors and the analytics services sourced in the cloud.

Figure 2 displays a proposed theoretical framework to assist firms in making the best decision in the use of cloud-based data analytics complemented by propositions 1-3 that results in increased efficiency in operation, better relationship with customers, and increased revenue in the decisionmaking process.

\section{FRAMEWORK EVALUATION}

\section{Vendor Denologix and Clients MANULIFE, AVIVA, and BMO Bank Group}

Although there are many different big data analytics vendors, the vendors that successfully manage contractual relationships with their clients will dominate the market. For example, Denologix clients have enjoyed success with their big data and business intelligence services. Denologix is a Canadian IT firm that offers information management planning, development, integration, and support services for transactional and business intelligence systems to its clients. Contracts between Denologix and most of its clients are not public. The following analyzes the propositions advanced in this study based upon publicly available information about Denologix and its clients.

\section{Contractual Challenges (Proposition 1)}

A firm's uncertainty is reduced when involved in the design of the services delivered or when given control over vendor performance. This alleviates concerns about underperformance and increases trust in the big data vendor. Denologix, in its relationship with Manulife Financial Corporation, 
Figure 2. Proposed framework for analysis of e-business management in the era of big data and cloud computing

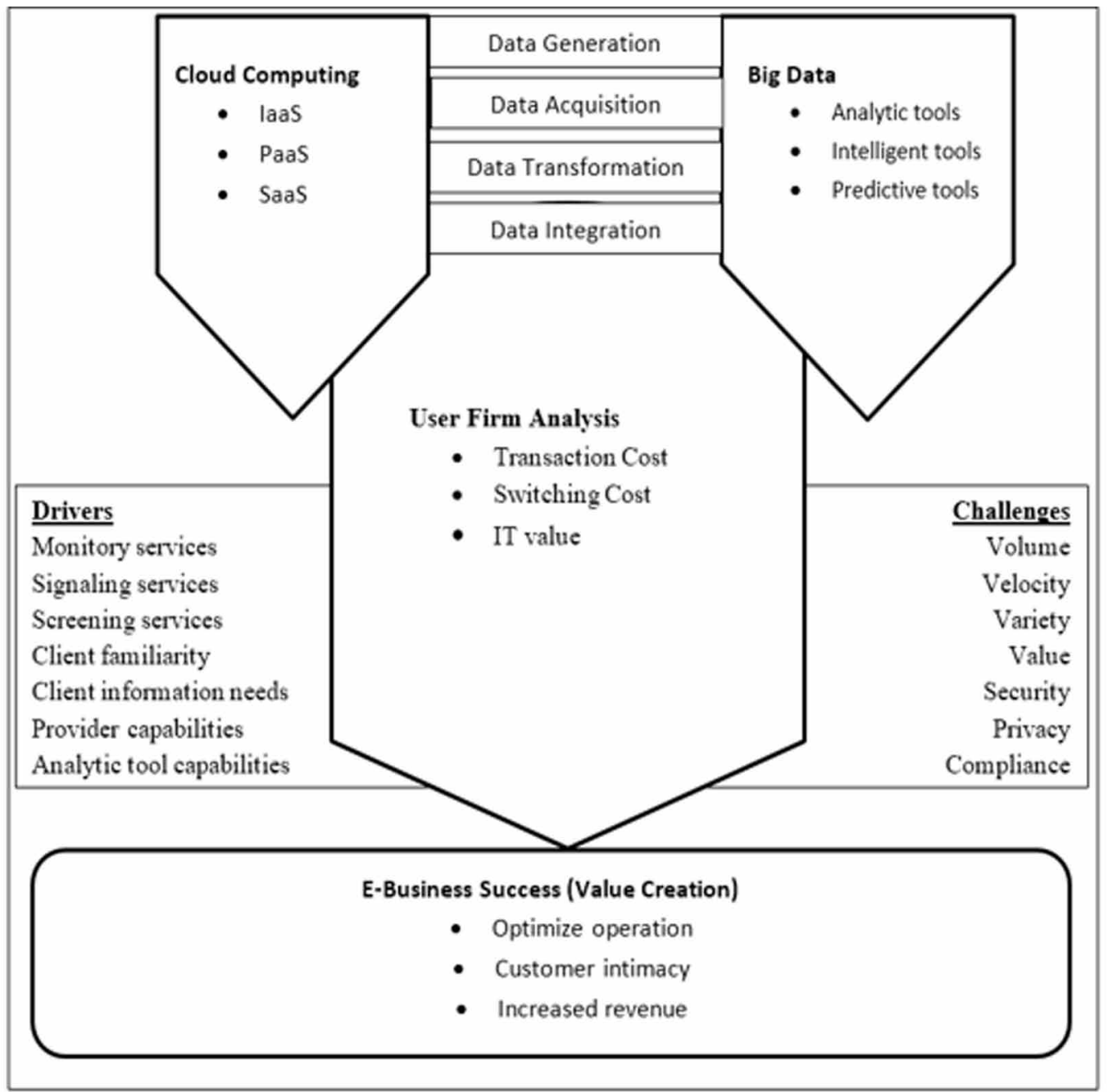

a Canadian based insurance and financial services provider company, has earned the trust of the insurance company to manage its most prized asset - customer data. A testimony of Denologix's reputation of trustworthiness is from a director of MANULIFE: "I have worked with Denologix for over a decade now. . . This vendor is amazing. I'm happy I chose Denologix and would do it again" (Denologix Information Management, 2019). When a vendor places the interest of clients at the behest of the shareholder, the vendor treats the trust of the e-business firm with care. Such a vendor will not shirk its responsibility to a business firm (Pavlou et al., 2007). Denologis has attempted to reduce concerns about potential shirking of its responsibility to its client. This is confirmed by a senior manager at AVIVA, another client:

Their team is very honest. Their leaders are very transparent and open. Partnerships like this, you don't find anywhere. I met very few vendors that I could say that I trusted. This vendor is amazing. I am happy I chose Denologix and would do it again. (Denologix Information Management, 2019) 


\section{Transaction Challenges (Proposition 2)}

E-businesses sometimes experience storage needs or analytical capability demand bursts due to external events, but they waste capacity if they overestimate the spike (Armbrust et al., 2010). This creates transaction challenges, including transaction costs, switching costs, and network externalities between big data vendors and their clients. These challenges will play a big role in creating value for clients. The more clients that are using a vendor's big data analytics, the more other consumers will be willing to use the vendors. This can only happen, however, if the vendor consistently adheres to standards. Many clients expect service level agreement uptimes and data accuracy of $99.99 \%$ or higher (Marston, Li, Bandyopadhyay, Zhang, \& Ghalsasi, 2011). This is a huge task for most vendors. Denologix has developed the Data Accuracy Index (dxINDEX) a benchmark to help companies understand if the data they are working with is performing at optimum levels. Denologix has worked with some of its clients to improve the quality and integration of their data. For instance, the director of the Canadian Imperial Bank of Commerce (CIBC) had this to say about their relationship with Denologix:

Their ability to understand customer needs is quite special. Denologix was very good at listening to us and coming up with solutions, which they were able to sell to our own internal clients easily. They know how to maintain the highest standard of professionalism and accountability. (Denologix Information Management, 2019)

\section{Countermeasures (Proposition 3)}

The provision of information that aids user firms to screen services of vendors is critical to realizing the value of cloud-based big data analytics. Clutch, a global market insight provider, makes information available to guide user firms in their decisions to select a good cloud-based big data analytics vendor. On its leader board, Clutch recognized Denologix as a Clutch Global Leader. This leader board includes over 475 companies from around the world. Clutch has ranked Denologix as one of the top 10 Big Data Analytics Companies in 2018 (Patrick, 2018). This has the potential to reduce uncertainty from any client of Denologix, including CIBC, may have. The Vice President of SAS had this to say about Denologix: "I have nothing but good things to say about them" (Denologix Information Management, 2019). This is an important monitoring and signaling service provided by Clutch. This leader board reports on the services of over 200 analytics vendors around the world. Clutch uses the services of expertise, as well as verified cases for its ranking of vendors. According to Clutch, some of the top big data brokers include Altoros, CBIG Consulting, KPI Partners, LatentView Analytics, Beyond the Arc, Anthem Marketing Solutions, VISUAL BI SOLUTIONS, InData Labs, cBEYONData (Formerly DCS Consulting), Denologix, Pinnacle Solutions, DataRoot Labs, Pragmatic Works, SoftwareMill, and Altar.io. Denologix's ranking demonstrates the value it has created for its clients. For example, Bank of Montreal, operating as BMO Financial Group, invested in an advanced IFRS 9 solution with the aid of Denologix, allowing BMO to exceed its credit risk monitoring and analysis target. Thus, the screening and signaling services provided by Clutch is a big step towards minimizing the chances of transaction failure.

\section{IMPLICATIONS}

This study, in addition to discussing cloud-based big data analytics technologies, presents a model that enables firms to create competitive parity by focusing on issues that threaten their contracts with vendors. The proposed framework systematically achieves competitive parity with data analytics by designing contracts that protect the objectives of e-business firms. Cloud-based big data clients can reduce uncertainty in their contracts with vendors and thus improve the 
probability of success using data analytics. The proposed theoretical framework is a decisionmaking tool for e-businesses and suggests that addressing transaction challenges such as shirking, underperformance, moral hazards, and data theft are fundamental to value creation instead of being merely implicit premises. Clients' efforts to maintain flexible and adaptable contracts with vendors will have to avoid some of these challenges and provide guarantees that help the process of value creation needed for competitive parity. This study enriches value creation research from an agency perspective. From a theoretical standpoint, AT and transaction cost theory provide insights into the governance of the provision of cloud-based data analytics services best suited for third parties vendors, the risks associated with providing services, and how to mitigate the risk effectively. The study reveals the essential elements, links, and path-to-value chains for an understanding of cloud-based big data analytic enabled value creation. As indicated by Gupta and George (2016), creating value with big data analytics is a complex process requiring human skills and intangible resources. The discussion in this study enriches the theoretical perspective and complements prior studies such as Xie, Wu, Xiao, and $\mathrm{Hu}$ (2016) on how big data resources could become cooperative assets.

\section{MANAGERIAL INSIGHTS}

Most IT managers must make the decision to use cloud-based analytic tools. However, managers are overloaded with different promises and capabilities by different vendors. This study highlights key factors to be considered when choosing and contracting as many managers are still in the early phase of technology adoption. The framework developed in this study provides a guide in the decision-making process to use cloud-based big data analytics. The study details how the interest of vendors and clients' firms might be misaligned and provides a new way of thinking for understanding the value of big data analytics. Organizations should carefully consider, understand, and reduce the risk of engaging the services of cloud-based data analytics and create competitive parity to enjoy the benefits of cloud computing as a strategic asset (Pakath, 2015). Additionally, an organization should analyze their preparedness by evaluating their organizations' management support and the complexity of integrating the cloud-based analytics with their local technology (Oliveira et al., 2014; Low et al., 2011). When selecting a vendor, IT managers should eliminate any vendor who poses contractual challenges to minimize risks.

Furthermore, IT managers will have to justify the selection of a vendor by evaluating both the direct and indirect way cloud-based analytics enhances their innovativeness (Oliveira et al., 2014). When the level of network effects generated using cloud-based analytics is high, IT managers will have to be concerned about transaction uncertainty, such as possible switching costs or adverse vendor selection. The level of competitive pressure in the industry influences the adoption and selection of cloud-based analytics tools, but their use should yield network benefits (Alshamaila et al., 2013).

Additionally, IT managers must consider security, privacy, and ethicality in selecting a cloudbased analytics vendor to optimize their returns (Sun et al., 2018). Even when IT managers make the best vendor selection, the institute practical measures such as monitoring, signaling, and screening to mitigate any unforeseen challenges. The more efficient the countermeasures are in the industry, the less concerned IT managers will be about contracts with vendors. In addition to the preceding, IT capability or competence in maintaining data (Hsu et al., 2014; Kwon et al., 2014) and carefully analyzing uncertainties about the involved costs in prioritizing the vendors should be considered (Raguseo, 2018). Figure 3 summarizes the key factors that influence IT managers' cloud-based analytics vendor selection. 
Figure 3. Vendor contracting decision factors

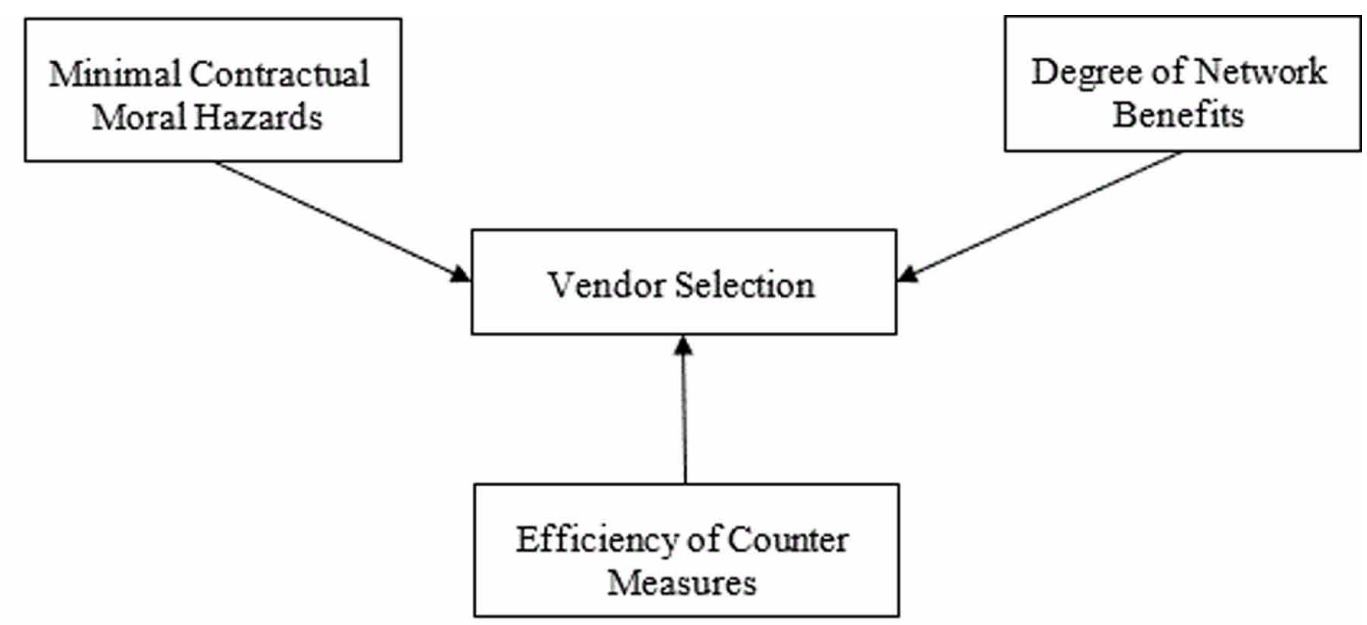

\section{CONCLUSION}

The framework proposed here opens new areas of research for examining the role of enablers and situations that would lead to delivering economic value to big data clients and vendors. This is because there is little information on SLA contracts and risk transfer designs that provide an optimal set of guidelines for clients considering the adoption of cloud-based big data analytics. The framework suggests that unique moral hazards, agent shirking, data theft, and switching cost issues should be included intimately in SLA design considerations. 


\section{REFERENCES}

Alshamaila, Y., Savvas, P., \& Feng, L. (2013). Cloud computing adoption by SMEs in the north east of England. Journal of Enterprise Information Management, 26(3), 250-275. doi:10.1108/17410391311325225

Amazon Web Services. (2013, June 1). Amazon Compute Service Level Agreement. https://aws.amazon.com/ ec2/sla/

Amit, R., \& Zott, C. (2001). Value creation in e-business. Strategic Management Journal, 22(6-7), 493-520. doi:10.1002/smj. 187

Ang, S., \& Straub, D. W. (1998). Production and transaction economies and IS outsourcing: A study of the US banking industry. Management Information Systems Quarterly, 22(4), 535-552. doi:10.2307/249554

Armbrust, M., Fox, A., Griffith, R., Joseph, A. D., Katz, R., Konwinski, A., Lee, G., Patterson, D., Rabkin, A., Stoica, I., \& Zaharia, M. (2010). A view of cloud computing. Communications of the ACM, 53(4), 50-58. doi:10.1145/1721654.1721672

Bakos, J. Y., \& Brynjolfsson, E. (1993). Information technology, incentives, and the optimal number of suppliers. Journal of Management Information Systems, 10(2), 37-53. doi:10.1080/07421222.1993.11517999

Behrend, T. S., Weibe, E. N., London, J. E., \& Johnson, E. C. (2011). Cloud computing adoption and usage in community colleges. Behaviour \& Information Technology, 30(2), 231-240. doi:10.1080/0144929X.2010.489118

Brodkin, J. (2008, August 11). Loss of customer data spurs closure of online storage service "The Linkup." Network World. https://www.networkworld.com/article/2274737/data-center/loss-of-customer-data-spurs-closureof-online-storage-service--the-linkup-.html

Chen, H., Chiang, R. H., \& Storey, V. C. (2012). Business intelligence and analytics: From big data to big impact. Management Information Systems Quarterly, 36(4), 1165-1188. doi:10.2307/41703503

Demirkan, H., \& Delen, D. (2013). Leveraging the capabilities of service-oriented decision support systems: Putting analytics and big data in cloud. Decision Support Systems, 55(1), 412-421. doi:10.1016/j.dss.2012.05.048

Denologix Information Management. (2019). Testimonials: Reviewed \& Approved. https://www.denologix. com/company/

Drozdiak, N., \& Schechner, S. (2015, October 6). EU court says data-transfer pact with U.S. violates privacy. The Wall Street Journal. https://www.wsj.com/articles/eu-court-strikes-down-trans-atlantic-safe-harbor-datatransfer-pact-1444121361

Eisenhardt, K. M. (1989). Agency theory: An assessment and review. Academy of Management Review, 14(1), 57-74. doi:10.5465/amr.1989.4279003

Gartner. (2015, February 13). Forecast: Public cloud service brokerage, 4Q14. https://www.gartner.com/ doc/2985118/forecast-public-cloud-service-brokerage

Gottschalk, P., \& Solli-Sæther, H. (2005). Critical success factors from IT outsourcing theories: An empirical study. Industrial Management \& Data Systems, 105(6), 685-702. doi:10.1108/02635570510606941

Gower, R. (2012). The economics of open data. Infonomics Limited. http://www.infonomics.ltd.uk/ blog/2012/10/25/the-economics-of-open-data/

Gupta, M., \& George, J. F. (2016). Toward the development of a big data analytics capability. Information \& Management, 53(8), 1049-1064. doi:10.1016/j.im.2016.07.004

Hashem, I. A. T., Yaqoob, I., Anuar, N. B., Mokhtar, S., Gani, A., \& Ullah Khan, S. (2015). The rise of "big data" on cloud computing: Review and open research issues. Information Systems, 47, 98-115. doi:10.1016/j. is. 2014.07 .006

Höchtl, J., Parycek, P., \& Schöllhammer, R. (2016). Big data in the policy cycle: Policy decision making in the digital era. Journal of Organizational Computing and Electronic Commerce, 26(1-2), 147-169. doi:10.1080/ 10919392.2015.1125187 
Hsu, P., Soumya, R., \& Yu-Yu, L. (2014). Examining cloud computing adoption intention, pricing mechanism, and deployment model. International Journal of Information Management, 34(4), 474-488. doi:10.1016/j. ijinfomgt.2014.04.006

Kwon, O., Namyeon, L., \& Bongsik, S. (2014). Data quality management, data usage experience and acquisition intention of big data analytics. International Journal of Information Management, 34(3), 387-394. doi:10.1016/j. ijinfomgt.2014.02.002

Liu, C. Z., Gal-Or, E., Kemerer, C. F., \& Smith, M. D. (2011). Compatibility and proprietary standards: The impact of conversion technologies in IT markets with network effects. Information Systems Research, 22(1), 188-207. doi:10.1287/isre.1090.0255

Low, C., Yahsueh, C., \& Mingchang, W. (2011). Understanding the determinants of cloud computing adoption. Industrial Management \& Data Systems, 111(7), 1006-1023. doi:10.1108/026355711111161262

Lowe, S. (2013, October 28). The cloud does not protect you from mistakes and failures. http://wikibon.org/ wiki/v/The_Cloud_Does_Not_Protect_You_From_Mistakes_and_Failures

Mann, A. (2013, January 7). Time to stop forgiving cloud providers for repeated failures. Andi Mann-Ubergeek. http://pleasediscuss.com/andimann/20130107/time-to-stop-forgiving-cloud-providers-for-repeated-failures/

Mao, J.-Y., Lee, J.-N., \& Deng, C.-P. (2008). Vendors' perspectives on trust and control in offshore information systems outsourcing. Information \& Management, 45(7), 482-492. doi:10.1016/j.im.2008.07.003

Marr, B. (2015). Big data: Using SMART big data, analytics and metrics to make better decisions and improve performance. Wiley.

Marston, S., Li, Z., Bandyopadhyay, S., Zhang, J., \& Ghalsasi, A. (2011). Cloud computing-The business perspective. Decision Support Systems, 51(1), 176-189. doi:10.1016/j.dss.2010.12.006

Mata, F. J., Fuerst, W. L., \& Barney, J. B. (1995). Information technology and sustained competitive advantage: A resource-based analysis. Management Information Systems Quarterly, 19(4), 487-505. doi:10.2307/249630

McAfee, R. P., \& McMillan, J. (1986). Bidding for contracts: A principal-agent analysis. The RAND Journal of Economics, 17(3), 326. doi:10.2307/2555714

McAfee, R. P., \& McMillan, J. (1987). Competition for Agency Contracts. The RAND Journal of Economics, 18(2), 296. doi: $10.2307 / 2555554$

Oliveira, T., Manoj, T., \& Mariana, E. (2014). Assessing the determinants of cloud computing adoption: An analysis of the manufacturing and services sectors. Information \& Management, 51(5), 497-510. doi:10.1016/j. im.2014.03.006

Pakath, R. (2015). Competing on the cloud: A review and synthesis of potential benefits and possible pitfalls. Journal of Organizational Computing and Electronic Commerce, 25(1), 1-27. doi:10.1080/10919392.2015.9 90771

Pallas, F. (2014). An agency perspective to cloud computing. In International Conference on Grid Economics and Business Models (pp. 36-51). Springer. https://link.springer.com/chapter/10.1007/978-3-319-14609-6_3

Patrick, S. (2018). Best big data analytics companies. Clutch. https://clutch.co/it-services/analytics

Pavlou, P. A., Liang, H., \& Xue, Y. (2007). Understanding and mitigating uncertainty in online exchange relationships: A principal-agent perspective. Management Information Systems Quarterly, 31(1), 105-136. doi: $10.2307 / 25148783$

Raguseo, E. (2018). Big data technologies: An empirical investigation on their adoption, benefits and risks for companies. International Journal of Information Management, 38(1), 187-195. doi:10.1016/j. ijinfomgt.2017.07.008

Subashini, S., \& Kavitha, V. (2011). A survey on security issues in service delivery models of cloud computing. Journal of Network and Computer Applications, 34(1), 1-11. doi:10.1016/j.jnca.2010.07.006

Susarla, A., Subramanyam, R., \& Karhade, P. (2010). Contractual provisions to mitigate holdup: Evidence from information technology outsourcing. Information Systems Research, 21(1), 37-55. doi:10.1287/isre.1080.0204 
Tiwana, A., \& Bush, A. (2007). A comparison of transaction cost, agency, and knowledge-based predictors of IT outsourcing decisions: A U.S.-Japan cross-cultural field study. Journal of Management Information Systems, 24(1), 259-300. doi:10.2753/MIS0742-1222240108

Troester, M. (2012). Big data meets big data analytics: Three key technologies for extracting real-time business value from the big data, that threatens to overwhelm traditional computing architectures [White Paper]. SAS Institute Inc.

Tuttle, B., Harrell, A., \& Harrison, P. (1997). Moral hazard, ethical considerations, and the decision to implement an information system. Journal of Management Information Systems, 13(4), 7-27. doi:10.1080/07421222.19 97.11518140

Tynan, D. (2013, October 23). How Box.com allowed a complete stranger to delete all my files. ITworld. https:// www.itworld.com/article/2833267/how-box-com-allowed-a-complete-stranger-to-delete-all-my-files.html

Williams, A. (2012, October 27). Amazon Web Services outage caused by memory leak and failure in monitoring alarm. TechCrunch. https://techcrunch.com/2012/10/27/amazon-web-services-outage-caused-by-memory-leakand-failure-in-monitoring-alarm/

Williamson, O. E. (1979). Transaction-cost economics: The governance of contractual relations. The Journal of Law \& Economics, 22(2), 233-261. doi:10.1086/466942

Wu, X., Zhu, X., Wu, G. Q., \& Ding, W. (2014). Data mining with big data. IEEE Transactions on Knowledge and Data Engineering, 26(1), 97-107. doi:10.1109/TKDE.2013.109

Xie, K., Wu, Y., Xiao, J., \& Hu, Q. (2016). Value co-creation between firms and customers: The role of big data-based cooperative assets. Information \& Management, 53(8), 1034-1048. doi:10.1016/j.im.2016.06.003

Yu, C.-C. (2016). A value-centric business model framework for managing open data applications. Journal of Organizational Computing and Electronic Commerce, 26(1-2), 80-115. doi:10.1080/10919392.2015.1125175

Emmanuel W. Ayaburi is an Assistant Professor in department of Information Systems in the Robert C. Vackar College of Business \& Entrepreneurship at The University of Texas Rio Grande Valley. He received his Ph.D. in Business Administration with a concentration in Information Systems from The University of Texas at San Antonio and his Master's in Business Administration from the Colorado Heights University. He holds a Bachelor of Science in Electrical Engineering KNUST in Ghana. Ayaburi's research interests include knowledge sharing, secure software design, information systems security and economics of information systems. His work has been publication in Information Systems Frontiers, Computers in Human Behavior, International Journal of Information Management and International Journal of Innovation and Technology Management. He has also published in a number of conference proceedings including International Conference on Information Systems (ICIS) and Americas Conferences in Information Systems (AMCIS).

Michele Maasberg is an Assistant Professor of Computer Science at Louisiana Tech University. She received her Ph.D. in Information Technology from the University of Texas at San Antonio, an M.S. in IT-Information Assurance from the University of Texas at San Antonio, and a B.S. from the U.S. Naval Academy. She has over a decade of experience in the cyber security field including information assurance management. She has been a Certified Information Systems Security Professional since 2013. Dr. Maasberg's research interests relate to cybersecurity, insider threats, and malware threat metrics, with applications to incident response \& loT and control systems security. She has published approximately 25 peer-reviewed articles in high impact journals and conference proceedings and her work has been funded by federal agencies. She is involved in numerous collaborative research projects with the National Science Foundation (NSF), Department of Defense (DoD), and industry.

Jaeung (Jake) Lee is an Assistant Professor (Clifford Ray King Endowed Professor) of Information Systems at the Louisiana Tech University. He received his Ph.D. in Information Systems from the Department of Management Science and Systems at the State University of New York at Buffalo. His primary areas of research interests include information security, emergency response management systems, and requirements management. His research has appeared in Decision Support Systems (DSS), Information Systems Frontiers (ISF) and conference proceedings such as ICIS, AMCIS, HICSS, DRW, WMSC, and IRM. 